\title{
DISTRIBUTION OF MOLAR INCISOR HYPOMINERALIZATION IN CHILDREN IN NORTHEAST BULGARIA. SEVERITY OF THE DYSPLASIA AND SENSITIVITY OF THE AFFECTED TEETH
}

\author{
Milena Georgieva-Dimitrova \\ Department of Pediatric Dentistry, Faculty of Dental Medicine, \\ Medical University of Varna
}

\begin{abstract}
INTRODUCTION: Molar incisor hypomineralization (MIH) is dysplasia associated with quantitative and qualitative disturbance in the development of the hard tooth tissues, described as a separate nosological unit for the first time in 2001. The distribution of the disease is significantly different in different geographic regions and varies from $2.4 \%$ to $40 \%$ with average distribution worldwide of $12.9 \%$ affecting over 17 million people all over the world. The modern science still cannot determine its exact etiological cause so it is considered that dysplasia is an idiopathic disease. Gene mutation is discussed as an etiological factor caused by the influence of environmental factors. Other causes might be systemic diseases, infections, intoxications, and use of different medicines.
\end{abstract}

AIM: The aim of the article is to investigate the distribution of MIH in relation to its severity and concomitant hyperesthesia.

MATERIALS AND METHODS: A retrospective study was conducted in the University Medical Dental Center - Varna, including 1183 children, examined with a standard set of dental instruments - dental mirror, probe and pincers. The examination was done after professional cleaning and drying of the teeth. The dental status was filled out in individual ambulatory cards for each patient.

RESULTS: The study investigated the distribution of MIH in Northeast Bulgaria and found that $6 \%$ of the children in the sample experienced dysplasia. In most of the cases (61\%), children had all 4 permanent molars affected by it. The results supported outcomes of other studies regarding the association between the severity of the dysplasia and the presence of concomitant hyperesthesia. With the increase in the severity of MIH tooth sensitivity increases.

CONCLUSION: Recent studies concerning the distribution of MIH have shown that dysplasia appears frequently in modern society. Severe hyperesthesia reflects the lifestyle and restricts the diet of children. In some cases, a radical surgical approach is consid-

Address for correspondence:

Milena Georgieva-Dimitrova

Faculty of Dental Medicine

Medical University of Varna

84 Tzar Osvoboditel Blvd

9002 Varna

e-mail:dr.milena.georgieva89@gmail.com ered, which may traumatize the psychological state of the child and increase the anxiety in future dental treatment.

Keywords: molar incisor hypomineralization, distribution, severity, sensitivity

Received: July 18, 2019

Accepted: September 6, 2019 


\section{INTRODUCTION}

As early as the Middle Ages human skulls with molar incisor hypomineralization (MIH) have been found (1). However, it was described as a separate nosological unit in 2001 for the first time $(2,3)$, after many studies concerning the distribution and the risk factors of this disease. As the name shows, dysplasia affects the first molars and incisors in the permanent dentition. Its incidence depends on the geographical region and the age group (4). MIH is defined as disturbance in the development of the hard tooth tissues with relatively high distribution (5). Dental hypoplasia is a defect in tooth development with quantitative and qualitative changes in the hard tissues (6). MIH is a specific form of hypoplasia defined more as hypomineralization $(2,7)$. The disease is defined as quantitative hypomineralization caused by systemic factors, affecting the enamel and the dentin of the first molars, with or without central incisor involvement $(3,8)$. The specific clinical appearance and the affected first molars and incisors presume a certain period of disturbance during the maturation stage of development of these teeth. The evidence about the etiology of this disease is unconvincing and recently it has been considered more often that MIH is an idiopathic condition. Genetic factors, describing a genetic mutation of the genes during the amelogenesis, are considered in its etiology (9).

The geographic differences in the distribution of the disease (10-15) and the deficiency of data about environmental risk factors $(16,17)$ support the idea that genetic factors provide the best explanation for the interesting phenotypic manifestation of $\mathrm{MIH}$. There are several main etiological factors associated with MIH: influence of environmental factors, pre- and perinatal disturbances, fluoride overdose, common diseases in childhood age and children with special needs and systemic diseases. Additional factors, which increase the risk of $\mathrm{MIH}$, are small gestational age and low weight of the newborn (18). It is discussed also that asthma, pneumonia, infection of respiratory tracts, otitis media, antibiotics, chronic tonsillitis, toxins in the breast milk, high fever in childhood age (19), environment with industrial wastes and toxins - dioxin (1), food pollution, newborn and neonatal factors, acute and chronic diseases in the childhood age, including their treatment, breast milk with fluoride content (8), hypoxia, hypocalcaemia, are associated with higher risk for MIH (16). During the intraoral examination it is possible to establish hypoplasia of the first molars and incisors with a tendency for upper teeth to be affected more often, compared with the mandibular ones. The occlusal surfaces are most commonly affected. The hypomineralized enamel is relatively soft, porous, and easily collapses right after the eruption of the teeth, forming non-carious defects. Thus these teeth often require large restorations. The affected teeth are with low mineralization and quite vulnerable to caries. This significantly increases the caries intensity (DMF index) in certain patients $(2,7,8,20)$.

\section{AIM}

The aim of the article is to investigate the distribution of $\mathrm{MIH}$, its severity and the concomitant hyperesthesia.

\section{MATERIALS AND METHODS}

A retrospective study of 1183 children with mixed dentition was conducted at the University Medical Dental Center of the Medical University of Varna in the period 2016-2019. The sample included all children in the age group 6-12 years treated at the University Medical Dental Center for the four-year period. The examination included assessment of the oral health status and the number of the teeth affected by MIH. The clinical examination and the diagnostics were performed after a professional cleaning of the dental plaque, supported by light and air drying of the tooth surfaces. Set of sterile dental instruments were used for every child - dental mirror, probe and pincers, and protective equipment for the pediatric dentist - mask, disposable nitrile gloves. An ambulatory card was filled out for every patient, showing the oral status, the presence of MIH, type and number of the affected teeth. The stains on the tooth surface were measured as present on every affected tooth, their opacity and color was registered in the dental status. Hyperesthesia of the affected teeth was subjectively assessed from anamnesis and clinical examination with external stimuli such as ice sticks, water stream, and air flow. The provoked and spontaneous pain was assessed as present or absent.

The prevalence of MIH was assessed with the proportion of affected children in the sample of 1183 
children between 6 and 12 years old. The severity of MIH was assessed by clinical observation of presence or absence of posteruptive enamel/dentin breakdown, extensive loss of hard tooth tissues, large restorations and defect fillings, teeth for endodontic treatment 4 years after the eruption.

Descriptive statistical analysis was carried out with the estimation of percentages of children and/or teeth with specific diseases/complications and 95\% confidence intervals, respectively. The association between MIH severity (independent variable) and the color of the stains, and between the MIH severity (independent variable) and thte hypersensitivity of the affected teeth was tested with Spearman's correlation. The level of statistical significance was set at $=0.05$.

\section{RESULTS}

The analysis revealed that 6\% (95\%CI: $4.31 \%$ 7.69\%) of the 1183 examined children in the sample were affected by MIH. Almost half of the 71 affected children - 42\% (95\%CI: 40.8\%- 43.7\%) had noticeable $\mathrm{MIH}$ on both molars and incisors. In $61 \%(95 \% \mathrm{CI}$ : 43.7\%- 78.8\%) of the 71 children with MIH all first permanent molars were affected by dysplasia. In addition, the severity of the dysplasia was more significant in the mandibular molars, and the reason for this was considered to be their earlier eruption and longer presence in the oral cavity until the moment of the examination. In $49 \%$ (95\% CI: $29 \%$ - 69.6\%) of the children with MIH it was observed that not all 4 permanent molars were affected by dysplasia (Fig. 1 ), as this may vary in the clinical manifestation - affection of 3 molars, 2 molars on one side of the jaws (maxillary and mandibular) and cross-affecting.

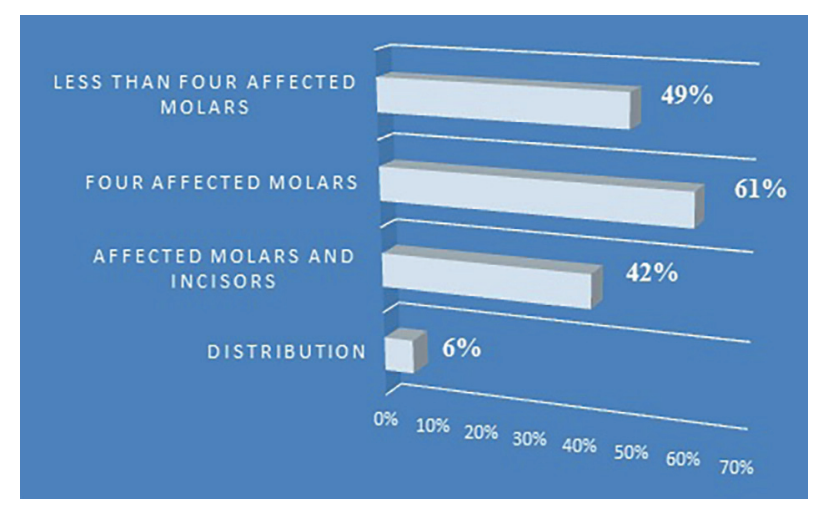

Fig. 1. Distribution of molar incisor hypomineralization
Fig. 2 represents the association between the severity of dysplasia and the type and color of the stains observed on the tooth surface - demarcated opacity spots. It was established that teeth with yellowbrown stains experience posteruptive breakdown of the enamel and dentin. Such teeth often lose their restorations and the breakdown continues. The teeth with such stains were observed in $83.7 \%$ (95\% CI: 81.3-86.3) out of the 284 examined first permanent molars affected by $\mathrm{MIH}$, and 31.2\% (95\% CI: $24.0-$ 38.1) of the severely damaged molars were planned for endodontic treatment after diagnosing the dysplasia. From the conducted observations an association was established between opaque yellow/brown spots and the severity of MIH ( $r=0.95)$. An exponential association was established between the type of the stains and the severity of the dysplasia $(\mathrm{p}<0.05)$.

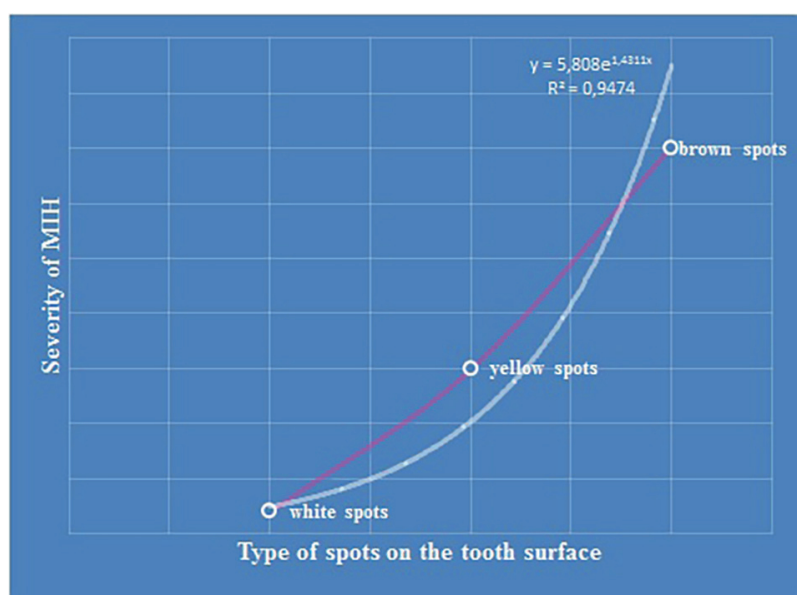

Fig. 2. Relationship between color of demineralized spots and the severity of $M I H$

Fig. 3 shows the association between the severity of MIH and the hyperesthesia of the teeth. An exponential dependence was observed between the examined components as well as a significant association between MIH severity and the higher sensitivity of the teeth. In comparison to the mild form of the dysplasia, we registered sporadic hypersensitivity from external stimuli (air, water). For teeth with a severe form of the disease a persisting and spontaneous hyperesthesia, disturbing the function was registered, which was the most common reason for the visit in the dental office. 


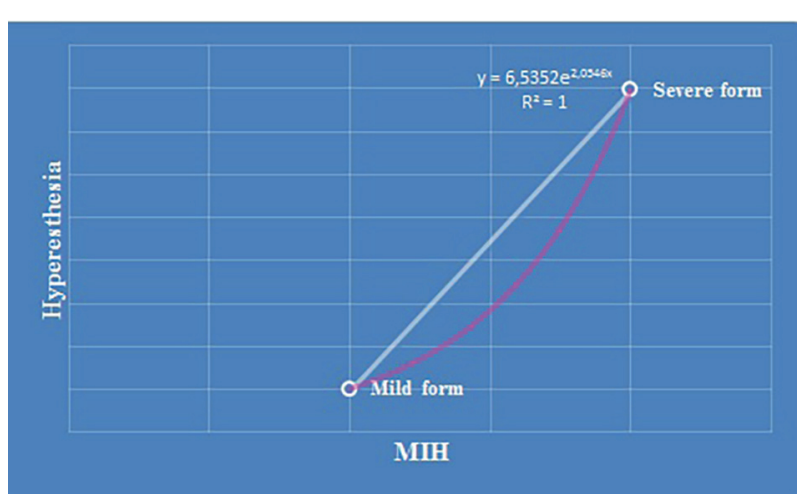

Fig. 3. Relationship between severity and hypersensitivity of the affected teeth

\section{DISCUSSION}

According to some authors the distribution of $\mathrm{MIH}$ varies from $2.4 \%$ to $40.2 \%(5,21)$. Recent metaanalysis report on the average global distribution of $\mathrm{MIH}$ reports that it affects $12.9 \%$, around 17.5 million people in 2016 (22). The accessible data concerning the distribution the results vary from $2.4 \%$ in Bulgaria (12) and Germany (11), 13.9\% in Norway (13), and $17 \%$ in Finland (10) to $37.3 \%$ in Denmark (15) and $40.2 \%$ in Brazil (14).

According to different literature sources the demineralized spots and their color define the severity of MIH on the enamel, mainly on the occlusal surface of the affected teeth, a severe form of MIH is considered that which often leads to enamel breakdown and fractures after the eruption of the tooth - non-carious defects. Demarcated white enamel stains without enamel loss are related to the mild form of MIH, suitable for non-operative treatment and represent an aesthetic defect (23-26).

Many authors have studied the high sensitivity of teeth affected by MIH, which is one of the main problems in their treatment. The dysplasia disturbs the patients as well as the dental practitioners (5). In cases of mild form of MIH a high sensitivity of the teeth is not that often, compared with the severe forms where the constant hypersensitivity of the affected teeth leads to low quality of life (25). In a study from 2019 the presence of hypersensitivity in teeth with different forms of MIH was reported, with the disease classified into three forms - mild, moderate, and severe (27). In mild forms a sensitivity with low intensity was established, as well as white demineralized stains on the enamel surface without enamel breakdown. In moderate forms the intensity of the sensitivity increases but not significantly. In addition there is an enamel loss after the eruption of the tooth. In the severe forms the intensity of the sensitivity is greatly increased. An enamel and dentin breakdown after the tooth eruption is registered with defect fillings on some teeth. The authors report an association between the severity of the dysplasia and the intensity of the sensitivity in proportional dependency. In addition, they report that the examination of the teeth with severe form of MIH is not objective enough since $90 \%$ of the teeth were affected by caries, which increases the sensitivity of the teeth by itself (27).

The complex approach for treatment of the affected children must include management of the behavior and anxiety to provide long and reliable restorations in painless conditions. The opportunities for treatment of MIH teeth are quite different - from preventive non-operative treatment, through restoration of the lost tissues to radical surgical extraction of the affected teeth. The choice and the indications of a treatment method depend on the severity of the demineralization, age of the patient, the social status and the expectations of the child and its parents $(8,28)$. The restorative methods of treatment are a relatively good choice for the MIH teeth with hypomineralization and non-carious defects, demanding restoration of the function and the aesthetics. A careful choice of restoration material is necessary, which includes composite materials for direct restoration, non-metal indirect ceramic constructions, and preformed metal crowns for the distal area (26). In cases of severely affected teeth a surgical extraction is considered supported by orthodontic or prosthetic treatment plan in advance (28).

\section{CONCLUSION}

The recent research concerning the distribution of MIH showed that dysplasia appears more often in the modern society. More studies related to the etiology of the MIH are necessary for better prophylaxis. The treatment of dysplasia is quite challenging because pain control in moderate and severe form is difficult, the adhesion of the restoration materials is compromised, and the breakdown of the enamel continues despite the medical intervention. The severe hyperesthesia affects the lifestyle and restricts 
the diet of the children. In some cases, a radical surgical approach is considered, which may traumatize the psychological state of the child and increase the anxiety in future dental treatment.

\section{REFERENCES}

1. Curzon ME, Ogden AR, Williams-Ward M, Cleaton-Jones PE. Case report: a medieval case of molar-incisor-hypomineralization. Br Dent J. 2015;219(12):583-7. doi: 10.1038/sj.bdj.2015.957.

2. Weerheijm KL. Molar incisor hypomineralization (MIH). Eur J Pediatr Dent. 2003;4(3):114-20.

3. Weerheijm KL, Jälevik B, Alaluusua S. Molar-incisor hypomineralisation. Caries Res. 2001;35(5):390-1. doi: 10.1159/000047479.

4. Denis M, Atlan A, Vennat E, Tirlet G, Attal JP. White defects on enamel: diagnosis and anatomopathology: two essential factors for proper treatment. Part 1. Int Orthod. 2013;11(2):139-65. doi: 10.1016/j.ortho.2013.02.014.

5. Rao MH, Aluru SC, Jayam C, Bandlapalli A, Patel N. Molar incisor hypomineralization. J Contemp Dent Pract. 2016;17(7):609-13.

6. Shafer WG, Hine MK, Levy BM, editors. Developmental disturbances of oral and paraoral structures. In: Textbook of oral pathology. 4th ed. Philadelphia (PA): WB Saunders; 1983. p. 2-85.

7. Gotler M, Ratson T. Molar incisor hypomineralization $(\mathrm{MIH})$ - a literature review. Refuat Hapeh Vehashinayim 2010;27(2):10-8.

8. Weerheijm KL, Duggal M, Mejare I, Papagiannoulis L, Koch G, Martens LC, et al. Judgement criteria for molar incisor hypomineralisation (MIH) in epidemiologic studies: a summary of the European meeting on MIH held in Athens. Eur J Paediatr Dent. 2003;4(3):110-3.

9. Jeremias F, Koruyucu M, Küchler EC, Bayram M, Tuna EB, Deeley K, et al. Genes expressed in dental development are associated with molar-incisor hypomineralization. Arch Oral Biol. 2013; 58(10):1434-42. doi: 10.1016/j. archoralbio.2013.05.005.

10. Alaluusua S, Lukinmaa PL, Koskimies M, Pirinen S, Hölttä P, Kallio M, et al. Developmental dental defects associated with long breast feeding. Eur J Oral Sci. 1996;104(5-6):493-7. doi: 10.1111/j.16000722.1996.tb00131.x.

11. Dietrich G, Sperling S, Hetzer G. Molar incisor hypomineralisation in a group of children and adoles- cents living in Dresden (Germany). Eur J Paediatr Dent. 2003;4(3):133-7.

12. Kukleva MP, Petrova SG, Kondeva VK, Nihtyanova TI. Molar incisor hypomineralization in 7- to 14-year-old children in Plovdiv, Bulgaria - an epidemiologic study. Folia Med (Plovdiv). 2008;50(3):71-5.

13. Schmalfuss A, Stenhagen KR, Tveit AB, Crossner CG, Espelid I. Canines are affected in 16-year-olds with molar-incisor hypomineralization (MIH): an epidemiological study based on the Tromsø study: "Fit Futures". Eur Arch Paediatr Dent. 2016;17(2):107-13. doi: 10.1007/s40368-015-0216-6.

14. Soviero V, Haubek D, Trindade C, Matta T, Poulsen S. Prevalence and distribution of demarcated opacities and their sequelae in permanent 1st molars and incisors in 7 to 13-year-old Brazilian children. Acta Odontol Scand. 2009;67(3):170-5. doi: 10.1080/00016350902758607.

15. Wogelius P, Haubek D, Poulsen S. Prevalence and distribution of demarcated opacities in permanent 1st molars and incisors in 6- to 8-year-old Danish children. Acta Odontol Scand. 2008;66(1):58-64. doi: 10.1080/00016350801926941.

16. Alaluusua S. Aetiology of molar-incisor hypomineralisation: a systematic review. Eur Arch Paediatr Dent. 2010;11(2):53-8. doi: 10.1007/BF03262713.

17. Serna C, Vicente A, Finke C, Ortiz AJ. Drugs related to the etiology of molar incisor hypomineralization: a systematic review. J Am Dent Assoc. 2016;147(2):120-30. doi: 10.1016/j.adaj.2015.08.011.

18. Brogårdh-Roth S, Matsson L, Klingberg G. Molar-incisor hypomineralization and oral hygiene in 10- to-12-yr-old Swedish children born preterm. Eur J Oral Sci. 2011;119(1): 33-9. doi: 10.1111/j.1600-0722.2011.00792.x.

19. Willmott NS, Bryan RA, Duggal MS. Molar-incisor hypomineralisation: a literature review. Eur Arch Paediatr Dent. 2008;9(4):172-9. doi: 10.1007/ BF03262633.

20. Kellerhoff NM, Lussi A. Molar-incisor hypomineralization. Schweiz Monatsschr Zahnmed. 2004;114(3):243-53.

21. Jälevik B. Prevalence and diagnosis of molar-incisor-hypomineralisation (MIH): A systematic review. Eur Arch Paediatr Dent. 2010;11(2):59-64. doi: 10.1007/BF03262714.

22. Schwendicke F, Elhennawy K, Reda S, Bekes K, Manton DJ, Krois J. Global burden of molar inci- 
Milena Georgieva-Dimitrova,

sor hypomineralization. J Dent. 2018;68:10-8. doi: 10.1016/j.jdent.2017.12.002.

23. de Souza JF, Fragelli CB, Jeremias F, Paschoal MAB, Santos-Pinto L, de Cássia Loiola Cordeiro R. Eighteen-month clinical performance of composite resin restorations with two different adhesive systems for molars affected by molar incisor hypomineralization. Clin Oral Investig. 2017;21(5):172533. doi: 10.1007/s00784-016-1968-Z.

24. Krämer N, Bui Khac NN, Lücker S, Stachniss V, Frankenberger R. Bonding strategies for $\mathrm{MIH}-$ affected enamel and dentin. Dent Mater. 2018;34(2):331-334. doi: 10.1016/j.dental.2017.11.015.

25. Lygidakis NA, Wong F, Jälevik B, Vierrou AM, Alaluusua S, Espelid I. Best clinical practice guidance for clinicians dealing with children presenting with molar-incisor hypomineralisation (MIH): An EAPD policy document. Eur Arch Paediatr Dent. 2010;11(2):75-81. doi: 10.1007/BF03262716.
26. William V, Burrow MF, Palamara JE, Messer LB. Microshear bond strength of resin composite to teeth affected by molar hypomineralization using 2 adhesive systems. Pediatr Dent. 2006;28(3):233-41.

27. Raposo F, de Carvalho Rodrigues AC, Lia ÉN, Leal SC. Prevalence of hypersensitivity in teeth affected by molar-incisor hypomineralization (MIH). Caries Res. 2019;53(4):424-30. doi: 10.1159/000495848.

28. Kotsanos N, Kaklamanos EG, Arapostathis K. Treatment management of first permanent molars in children with molar-incisor-hypomineralisation. Eur J Paediatr Dent. 2005;6(4):179-84. 